\title{
Very preterm birth is a risk factor for increased systolic blood pressure at a young adult age
}

\author{
Mandy G. Keijzer-Veen • Arzu Dülger • \\ Friedo W. Dekker • Jeroen Nauta • \\ Bert J. van der Heijden
}

Received: 28 April 2009 /Revised: 1 October 2009 /Accepted: 7 October 2009 /Published online: 15 December 2009

(C) The Author(s) 2009. This article is published with open access at Springerlink.com

\begin{abstract}
Children born very prematurely who show intrauterine growth retardation (IUGR) are suggested to be at risk of developing high blood pressure as adults. Renal function may already be impaired by young adult age. To study whether very preterm birth affects blood pressure in young adults, we measured 24-h ambulatory blood pressure (Spacelabs $^{\mathrm{TM}} 90207$ device) and renin concentration in 50 very premature individuals ( $<32$ weeks of gestation), either small (SGA) or appropriate (AGA) for gestational age (21 SGA, 29 AGA), and 30 full-term controls who all were aged 20 years at time of measurement. The mean (standard deviation) daytime systolic blood pressure in SGA and AGA prematurely born individuals, respectively, was 122.7 (8.7) and $123.1(8.5) \mathrm{mmHg}$. These values were, respectively, $3.6 \mathrm{mmHg}[95 \%$ confidence interval $(\mathrm{CI})-0.9$ to 8.0] and $4.2 \mathrm{mmHg}(95 \%$ CI $0.4-8.0$ ) higher than in controls [119.6 (7.6)]. Daytime diastolic blood pressure and nighttime blood pressure did not differ between groups. We conclude that individuals born very preterm have higher daytime systolic blood pressure and higher risk of hypertension at a young adult age.
\end{abstract}

Keywords Hypertension - Intrauterine growth retardation . Premature birth - Developmental origins of health and disease $\cdot$ Ambulatory blood pressure monitor $\cdot$ Blood pressure

\footnotetext{
M. G. Keijzer-Veen $(\bowtie) \cdot$ A. Dülger $\cdot$ J. Nauta $•$

B. J. van der Heijden

Department of Pediatric Nephrology, Erasmus MC - Sophia

Children's Hospital, University Medical Center Rotterdam,

P.O. Box 2060, 3000 CB Rotterdam, The Netherlands

e-mail: m.keijzer-veen@erasmusmc.nl

F. W. Dekker

Department of Clinical Epidemiology,

Leiden University Medical Center,

P.O. Box 9600, 2300 RB Leiden, The Netherlands
}

\author{
Abbreviations \\ IUGR Intrauterine growth restriction \\ SGA Small for gestational age \\ AGA Appropriate for gestational age \\ POPS Project of Preterms and Small for Gestational Age \\ Infants \\ ABPM Ambulatory blood pressure monitor \\ SBP Systolic blood pressure \\ DBP Diastolic blood pressure \\ MAP Mean arterial pressure \\ SD Standard deviation \\ SDS Standard deviation score
}

\section{Introduction}

Over the past 20 years, evidence has accumulated indicating that intrauterine growth restriction (IUGR) affects normal development of the kidneys and vascular system, thereby increasing the likelihood of hypertension and/or cardiovascular diseases [1-4]. Impaired fetal kidney development leading to nephron deficit is considered an important pathway in the development of hypertension after IUGR birth [5-10]. Apart from IUGR, premature birth may contribute to the development of disease at adult age [11-15]. We demonstrated poorer renal function in very preterm individuals at age 19 years born with IUGR compared with very preterm individuals born with appropriate birth weight. Blood pressure did not differ between these groups $[16,17]$. The findings from that study seemed to point to higher-than-normal prevalence of hypertension in both groups, but evidence was inconclusive for lack of controls. 
In addition we performed a prospective follow-up study at age 20 years of individuals born very prematurely and in controls born after full gestation [18]. Data obtained included inulin and para-amino hippuric acid clearance before and after renal stimulation, renal functional reserve capacity, microalbuminuria, renal size, blood pressure during renal function tests, 24-h ambulatory blood pressures and renin concentration. The glomerular filtration rate (GFR) did not differ between groups. The effective renal plasma flow was impaired, however, in preterm individuals with IUGR. These also showed increased microalbuminuria and higher systolic blood pressure (SBP) compared with controls. Renal size was related to GFR and effective renal plasma flow and was stunted, both regarding length and volume [19]. In this article we report more detailed results of ambulatory blood pressure monitoring $(\mathrm{ABPM})$ in these individuals.

\section{Methods}

\section{Study population}

We recruited three groups of 20-year-olds: (1) Born very prematurely ( $<32$ weeks) and small for gestational age (SGA). (2) Born very prematurely and appropriate for gestational age (AGA). (3) Born full term (37-42 weeks) and appropriate for gestational age (controls). Individuals in the first two groups participate in a follow-up study of a Dutch birth cohort (all born in 1983) including $94 \%(N=1,338)$ of all live-born individuals in The Netherlands with gestational age $<32$ weeks and/or birth weight $<1,500 \mathrm{~g}$. This is the POPS cohort: Project on Preterms and Small for Gestational Age Infants [20]. The so-called POPS 19 study included 596 $(62.1 \%)$ of the 959 survivors until age 19 years. Four hundred and twenty-two of those were born with a gestational age $<32$ weeks, and 174 with a gestational age $\geq 32$ weeks but with a birth weight $<1,500 \mathrm{~g}$. Nonresponders of this study differed from responders by male gender, nonDutch origin, low maternal education, severe handicap, and special education. SGA status did not differ between responders and nonresponders [21].

Participants in our study were recruited from the 422 individuals born with a gestational age $<32$ weeks who participated in the POPS 19 study (see also Fig. 1). Recruitment of SGA individuals started with the lowest birth weight adjusted for gestational age $[\leq-2.0$ standard deviation scores (SDS) $N=29$ ] that of AGA individuals with the highest birth weight adjusted for gestational age (0 to $+2.0 \mathrm{SDS}, N=205$ ). This strategy was aimed at gaining great contrast between groups. For the sake of convenience, those living closest to the Erasmus MC University Medical Center, Rotterdam, The Netherlands, were recruited first. Controls were term born (37-42 weeks of gestation) with

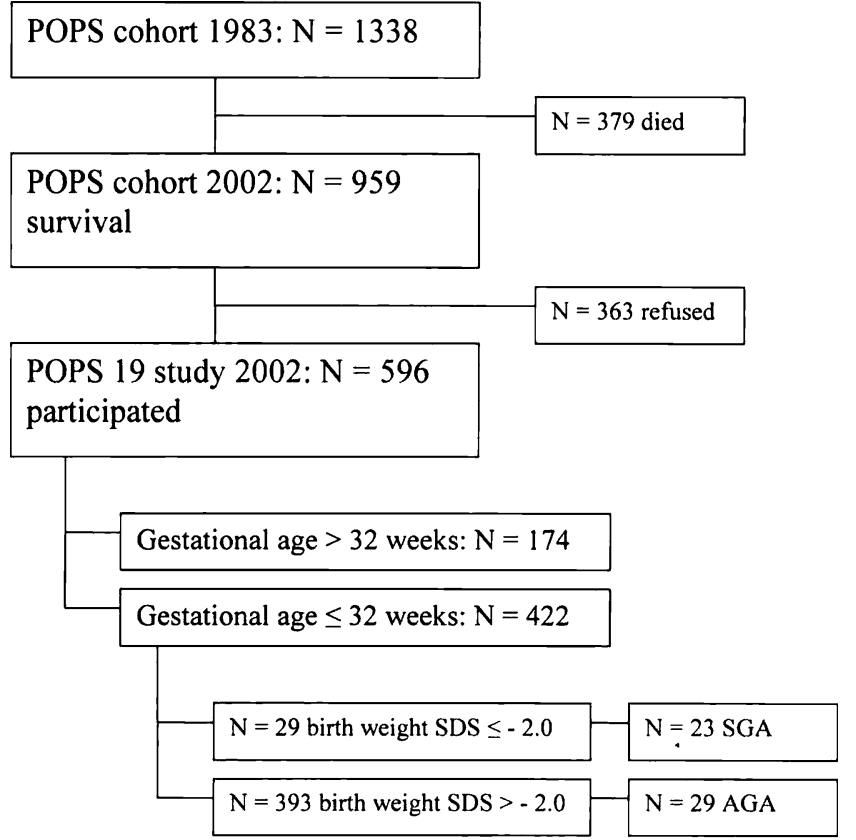

\section{Recruitment in Erasmus MC medical school \\ $\mathrm{N}=30$ Controls}

Fig. 1 Flow chart of study inclusion

normal birth weight ( -2 to +2 SDS) between 1 January 1982 and 31 December 1984. They were all medical students at Erasmus MC and had been recruited by distribution of flyers in the medical school that mentioned as inclusion criteria normal gestational age, normal birth weight, and birth years 1982-1984.

\section{Data collection}

Patient characteristics Present weight, height, and body mass index (BMI) were measured and converted to SDS [22]. Birth weights, gestational ages, obstetric, and perinatal parameters of the prematurely born individuals were derived from the POPS database (TNO Quality of Life, Leiden, The Netherlands). Birth weight was converted to SDS adjusted for gestational age using Swedish reference standards [23] and was considered a measure of IUGR [birth weight (SDS)]. Birth weights and gestational ages of controls were preferably obtained from birth records, midwives' administration, birth announcement cards, or diaries. Otherwise, they were derived from mother's recall. If reliable data on birth weight and gestational age could not be obtained, controls were not included in the study.

\section{Blood pressure measurement}

All participants underwent three blood pressure measurements at a minimum interval of $1 \mathrm{~min}$ in sitting position 
after at least $15 \mathrm{~min}$ of rest. Measurements were at the nondominant arm using a calibrated automatic blood pressure device (Hewlett Packard). The mean of these three measurements was used in the statistical analysis (baseline blood pressure). Thereafter, SBP and diastolic blood pressure (DBP) were measured with a Spacelabs ${ }^{\mathrm{TM}} 90207$ ambulatory blood pressure monitor (ABPM) at the nondominant upper arm over $24 \mathrm{~h}$. Cuff size was adjusted for upper arm length [24]. Reading frequency was programmed for every $20 \mathrm{~min}$ from $7 \mathrm{a} . \mathrm{m}$. to $11 \mathrm{p} . \mathrm{m}$. and for every hour between 11 p.m. and 7 a.m. Participants reported exercise, bedtime, and wake-up time in a diary. Mean daytime (awake), night-time (sleeping), and overall blood pressure values were calculated, and absolute and relative differences in day- and night-time blood pressure were derived. Hypertension criteria were those suggested by the European Society of Hypertension [25]. In 24-h measurements, normal blood pressure is defined as $\leq 130 / 80 \mathrm{mmHg}$ and hypertension as $>135 / 85 \mathrm{mmHg}$. Normal daytime blood pressure is defined as $\leq 135 / 85 \mathrm{mmHg}$ and daytime hypertension as $>140 / 90 \mathrm{mmHg}$. Normal nocturnal blood pressure is defined as $<120 / 70$ and nocturnal hypertension as $>125 / 75$. Blood pressure load is defined as the percentage of measurements exceeding the 95th percentile, adjusted for awakeness and sleep [26].

Blood was drawn at rest after baseline blood pressure measurement. Renin (ng Al/mg per hour) was quantitated by its capacity to generate angiotensin I from excess substrate angiotensinogen measured by an in-house radioimmunoassay, as described previously [27]. All participants also underwent a renal function test and renal ultrasonography by a method described elsewhere [18]. Data on plasma creatinine levels $(\mu \mathrm{mol} /$ liter $)$, creatinine clearance $\left(\mathrm{ml} / \mathrm{min} / 1.73 \mathrm{~m}^{2}\right)$, and total kidney length $(\mathrm{cm})$ and volume $\left(\mathrm{cm}^{3}\right)$ were also recorded.

\section{Informed consent and institutional approval}

Informed consent was obtained after oral and written information. All participants were able to provide consent with understanding and in writing. The Erasmus MC review board approved the study protocol.

\section{Statistics}

Statistical analysis was performed with SPSS 15.0 software. Multiple regression analysis served to analyze group differences adjusted for gender. Two group comparisons were performed to analyze the effect of IUGR (SGA vs AGA) and gestational age (AGA vs controls). Results are presented as mean, standard deviation (SD) and $P$ value for the differences between groups. Multiple regression analysis was also performed to analyze relations between renin concentration and blood pressure adjusted for gender. Pearson's chi-square tests were performed to analyze differences in perinatal factors between AGA and SGA groups and to compare prevalences of current hypertension between all groups. Statistical significance was considered at the level of $5 \%$.

\section{Results}

Eighty-two individuals participated: 23 SGA, 29 AGA, and 30 controls. Thirty-five individuals registered with the research team as possible controls. Five were excluded because birth weight or gestational age were uncertain. For 12 of the 30 controls $(40 \%)$, birth weight or gestational age were derived from maternal recall. Data of two of the SGA individuals were excluded from data analysis. In one, blood pressure measurements may have been unreliable because of frequent premature heartbeats. The second suffered an unrelated allergic episode prior to ABPM measurement. These two participants did not undergo ABPM. Table 1 shows baseline characteristics of the remaining 80 participants by study group. SGA individuals had significantly lower weight and height than AGA individuals and controls. BMI at age 20 did not differ between the three groups. Table 2 shows that proportions of mothers with hypertension during pregnancy, and cardiotocographic deterioration in the SGA group were significantly higher (Pearson $\chi^{2}$ test: $P<0.05$ ) than those in the AGA groups. Infant respiratory distress syndrome also occurred more frequently in AGA individuals. Other prenatal, perinatal, and postnatal parameters were equally distributed (Table 2). There were no gender differences for birth weight $(\mathrm{g})$, birth weight SDS and gestational age. At age 20, men were taller (mean height difference $13.4 \mathrm{~cm} \mathrm{95 \%} \mathrm{CI} \mathrm{10.0-16.9)} \mathrm{and}$ heavier (mean weight difference $12.3 \mathrm{~kg} \mathrm{95 \%} \mathrm{CI} \mathrm{7.7-17.0)}$ than women, but BMI (mean difference $0.6 \mathrm{~kg} / \mathrm{m}^{2} 95 \%$ CI -0.7 to 1.9 ) did not differ significantly.

Baseline and ambulatory blood pressure monitor measurements

Men had significantly higher SBP and significantly lower heart rate than women $(P<0.05)$. All regression analyses were adjusted for gender (Table 3 ).

Prematurity Baseline SBP in AGA individuals was $8.4 \mathrm{mmHg}$ higher than in controls $(95 \%$ CI $4.1 ; 12.7, P<$ 0.001). Ambulatory daytime SBP in AGA individuals was $4.2 \mathrm{mmHg}$ higher $(95 \% \mathrm{CI} 0.4-8.0, P=0.03)$ than that in controls. Baseline DBP, ambulatory DBP, heart frequency (HF), mean arterial pressure (MAP), and nocturnal SBP dip 
Table 1 Participant baseline characteristics

\begin{tabular}{|c|c|c|c|c|c|c|c|c|}
\hline & \multicolumn{2}{|l|}{ SGA } & \multicolumn{2}{|l|}{ AGA } & \multicolumn{2}{|c|}{ Controls } & \multirow[t]{2}{*}{ SGA vs AGA } & \multirow[t]{2}{*}{ AGA vs Controls } \\
\hline & \multicolumn{2}{|l|}{$N=21$} & \multicolumn{2}{|l|}{$N=29$} & \multicolumn{2}{|l|}{$N=30$} & & \\
\hline & Mean & $\mathrm{SD}$ & Mean & SD & Mean & $\mathrm{SD}$ & $P$ value & $P$ value \\
\hline Age (year) & 20.7 & 0.3 & 20.7 & 0.4 & 20.7 & 0.8 & 0.938 & 0.968 \\
\hline Males $[\%$ (number)] & 38 & 8 & 38 & 11 & 47 & 14 & 0.991 & 0.497 \\
\hline BW (g) & 858 & 132 & 1489 & 257 & 3632 & 489 & $<0.00^{*}$ & $<0.001^{*}$ \\
\hline GA (weeks) & 30.6 & 1.1 & 29.5 & 1.4 & 40.2 & 1.3 & $<0.004^{*}$ & $<0.001^{*}$ \\
\hline BW-SDS & -2.2 & 0.3 & 0.7 & 0.5 & 0.3 & 1.0 & $<0.001^{*}$ & 0.052 \\
\hline Body height $(\mathrm{cm})$ & 168 & 11 & 174 & 7.7 & 176 & 10 & $0.001^{*}$ & 0.583 \\
\hline Body height (SDS) & -1.2 & 1.1 & -0.2 & 0.9 & -0.1 & 1.1 & $0.001^{*}$ & 0.568 \\
\hline Body weight (kg) & 60.7 & 9.1 & 67.4 & 12.0 & 71.4 & 11.7 & $0.011^{*}$ & 0.274 \\
\hline Body weight (SDS) & -1.1 & 1.3 & -0.2 & 1.0 & 0.2 & 1.2 & $0.011^{*}$ & 0.259 \\
\hline BMI $\left(\mathrm{kg} / \mathrm{m}^{2}\right)$ & 21.7 & 2.6 & 22.1 & 2.8 & 22.9 & 2.8 & 0.524 & 0.319 \\
\hline
\end{tabular}

Data expressed by mean [standard deviation (SD)] and regression $P$ value adjusted for gender, except for gender $\left(\chi^{2}\right)$

$S G A$ small for gestational age prematurely born individuals, $A G A$ appropriate for gestational age prematurely born individuals, controls appropriate for gestational age term-born individuals, $B W$ birth weight, $G A$ gestational age, $B W-S D S$ birth weight standard deviation score, $B M I$ body mass index

${ }^{*} P<0.05$

did not differ between these groups. Night-time SBP was slightly, though not significantly, higher in AGA individuals (AGA $3.6 \mathrm{mmHg}$ higher with $95 \% \mathrm{CI}-0.9$ to 8.1 , $P=0.12$ ). SBP load in AGA individuals was $5.5 \%$ higher than that in controls $(P=0.049)$. DBP load did not differ between groups. Baseline MAP in AGA individuals was higher than that in controls.

Renal ultrasonography revealed subclinical renal anomalies in eight prematurely born individuals (three SGA and five AGA), i.e. nephrocalcinosis $(N=1)$, unilateral pyelocaliceal dilatation $(N=3)$, ureteropelvic junction obstruction $(N=1)$, ureter dilatation $(N=1)$, extrarenal pelvis $(N=1)$, ureter duplication and ureterocele $(N=1)$. In a separate analysis without these individuals, night-time SBP was also significantly higher in AGA individuals compared with controls $(P=0.035)$, and SBP load was no longer significantly different $(P=0.062)$. Baseline SBP, 24-h SBP, and daytime SBP all remained significantly higher in AGA individuals compared with controls $(P<0.05)$.

IUGR Regarding both day- and night-time values, the SGA and AGA groups did not differ significantly in SBP, DBP, MAP, HF, and blood pressure load.
Table 2 Obstetric and perinatal parameters in the prematurely born groups

$S G A$ small for gestational age prematurely born individuals, $A G A$ appropriate for gestational age prematurely born individuals * Pearson $\chi^{2}$ test $P<0.05$

\begin{tabular}{|c|c|c|c|c|}
\hline \multirow[t]{2}{*}{ Parameter } & \multicolumn{2}{|l|}{ SGA (21) } & \multicolumn{2}{|l|}{ AGA (29) } \\
\hline & Number & $\%$ & Number & $\%$ \\
\hline Hypertension during pregnancy ${ }^{*}$ & 13 & 62 & 2 & 7 \\
\hline Diabetes gravidarum & 1 & 5 & 2 & 7 \\
\hline Blood group Antagonism & 0 & 0 & 0 & 0 \\
\hline Pre-existing maternal disease & 2 & 10 & 1 & 3 \\
\hline Premature rupture of membranes & 2 & 10 & 8 & 28 \\
\hline Amnionitis & 0 & 0 & 3 & 10 \\
\hline Cardiotocographic deterioration ${ }^{*}$ & 15 (3 unknown) & 71 & 4 (7 unknown) & 14 \\
\hline Use of corticosteroids & 2 & 10 & 8 & 28 \\
\hline Apgar score $<7$ after 5 minutes & 1 (2 unknown) & 5 & 1 (2 unknown) & 3 \\
\hline Infant respiratory distress syndrome ${ }^{*}$ & 5 & 24 & 16 & 55 \\
\hline Sepsis & 8 & 38 & 13 & 45 \\
\hline Convulsions & 0 & 0 & 0 & 0 \\
\hline
\end{tabular}


Table 3 Mean 24-h, daytime and night-time blood pressure values, blood pressure load, renal function and size, and renin concentration in SGA and AGA preterms and controls

\begin{tabular}{|c|c|c|c|c|c|c|c|c|}
\hline & \multirow{2}{*}{\multicolumn{2}{|c|}{$\frac{\mathrm{SGA}}{N=21}$}} & \multirow{2}{*}{\multicolumn{2}{|c|}{$\frac{\mathrm{AGA}}{N=29}$}} & \multirow{2}{*}{\multicolumn{2}{|c|}{$\begin{array}{l}\text { Controls } \\
N=30\end{array}$}} & \multirow{3}{*}{$\begin{array}{l}\text { SGA vs AGA } \\
\text { value }\end{array}$} & \multirow{3}{*}{$\begin{array}{l}\text { AGA vs Controls } \\
P \text { value }\end{array}$} \\
\hline & & & & & & & & \\
\hline & Mean & SD & Mean & SD & Mean & $\mathrm{SD}$ & & \\
\hline Baseline SBP (mmHg) & 124.1 & 10.9 & 125.4 & 9.9 & 117.7 & 8.2 & 0.641 & $<0.001^{*}$ \\
\hline Baseline DBP (mmHg) & 70.0 & 9.8 & 70.0 & 7.8 & 68.0 & 7.1 & 0.997 & 0.336 \\
\hline \multicolumn{9}{|l|}{ 24-h blood pressure } \\
\hline $\mathrm{SBP}(\mathrm{mmHg})$ & 118.0 & 7.9 & 119.4 & 8.6 & 115.9 & 7.9 & 0.534 & $0.042^{*}$ \\
\hline DBP (mmHg) & 68.4 & 7.3 & 68.5 & 4.9 & 67.6 & 6.4 & 0.994 & 0.600 \\
\hline \multicolumn{9}{|l|}{ Daytime blood pressure } \\
\hline $\mathrm{SBP}(\mathrm{mmHg})$ & 122.7 & 8.7 & 123.1 & 8.5 & 119.6 & 7.6 & 0.816 & $0.031^{*}$ \\
\hline $\mathrm{DBP}(\mathrm{mmHg})$ & 73.0 & 8.0 & 72.2 & 5.1 & 71.7 & 6.0 & 0.652 & 0.819 \\
\hline \multicolumn{9}{|l|}{ Night-time blood pressure } \\
\hline SBP $(\mathrm{mmHg})$ & 107.9 & 8.3 & 110.9 & 9.1 & 107.9 & 9.4 & 0.254 & 0.118 \\
\hline DBP (mmHg) & 58.1 & 7.3 & 59.6 & 5.6 & 58.8 & 7.1 & 0.434 & 0.556 \\
\hline SBP load (\%) & 17.9 & 20.0 & 18.1 & 20.2 & 12.3 & 16.5 & 0.817 & $0.049^{*}$ \\
\hline DBP load (\%) & 10.1 & 14.8 & 7.7 & 7.5 & 13.8 & 17.3 & 0.795 & 0.251 \\
\hline Nocturnal dip SBP (\%) & 12.0 & 5.3 & 9.9 & 4.4 & 9.8 & 9.5 & 0.204 & 0.928 \\
\hline Nocturnal dip DBP (\%) & 20.3 & 7.3 & 17.3 & 6.4 & 18.1 & 6.5 & 0.161 & 0.497 \\
\hline Creatinine clearance $\left(\mathrm{ml} / \mathrm{min} / 1.73 \mathrm{~m}^{2}\right)$ & 106.5 & 22.1 & 119.4 & 31.0 & 109.6 & 31.9 & 0.116 & 0.255 \\
\hline Creatinine $(\mu \mathrm{mol} / \mathrm{l})$ & 71.6 & 9.1 & 70.7 & 12.3 & 72.0 & 13.2 & 0.811 & 0.881 \\
\hline Total kidney length $(\mathrm{cm})$ & 20.3 & 1.4 & 20.7 & 1.6 & 21.7 & 1.8 & 0.238 & 0.087 \\
\hline Total kidney volume $\left(\mathrm{cm}^{3}\right)$ & 252.5 & 80.2 & 263.2 & 49.3 & 310.3 & 79.7 & 0.585 & $0.021^{*}$ \\
\hline Renin (ng Al/ml/h) & 1.8 & 0.8 & 2.2 & 0.9 & 2.3 & 1.1 & 0.097 & 0.852 \\
\hline
\end{tabular}

Data expressed by mean [standard deviation (SD)] and regression $P$ value adjusted for gender

$S G A$ small for gestational age prematurely born individuals, $A G A$ appropriate for gestational age prematurely born individuals, controls appropriate for gestational age term-born individuals, $S B P$ systolic blood pressure, $D B P$ diastolic blood pressure

${ }^{*} P<0.05$

\section{Hypertension prevalence}

Table 4 shows equal distribution of normal blood pressure, borderline hypertension, and hypertension prevalences (Pearson $\chi^{2}=6,135 ; P=0.197$ ) between groups. No difference was found in daytime or night-time prevalences between groups.

Nocturnal dipping (decrease in blood pressure $>10 \%$ ) was observed in two of 21 SGA, four of 29 AGA, and four of 30 controls. In this regard, no significant difference was reached between groups (Pearson $\chi^{2}=0.233, P=0.890$ ), Renin concentration (ng Al/ml per hour) was available in 79 of the 80 individuals (Table 3). Renin concentration in men was not significantly higher than that in women (mean difference $0.33 \mathrm{ng} \mathrm{Al} / \mathrm{ml} / \mathrm{h}, 95 \% \mathrm{CI}-0.1$ to 0.7 ). Renin concentration in SGA individuals was 0.42 lower than that in AGA individuals $(95 \% \mathrm{CI}-0.08$ to $0.92, P=$ $0.097)$ and 0.48 lower than that in controls $(95 \% \mathrm{CI}-0.09$ to $1.05, P=0.10)$. No relation between renin concentration and SBP or DBP was found. In a linear regression analysis, renin concentration was not related to birth weight as a continuous variable (both SDS and g) or to gestational age.

Renal function and size

Renal size in controls was larger than that in AGA individuals. Renal size did not significantly differ between AGA and SGA individuals. Plasma creatinine and creatinine clearance did not differ between groups. Renal function and size were not correlated with SBP or DBP values.

\section{Discussion}

In this study, individuals born very prematurely ( $<32$ weeks) showed higher SBP at age 20 years than did full-term individuals of the same age. Our findings are consistent, 
Table 4 Prevalence of hypertension using the criteria for hypertension measured with an ambulatory blood pressure monitor (ABPM) defined by the European Society of Hypertension [42]

\begin{tabular}{|c|c|c|c|c|c|c|}
\hline & \multicolumn{2}{|c|}{ SGA } & \multicolumn{2}{|c|}{ AGA } & \multicolumn{2}{|c|}{ Controls } \\
\hline & $N$ & $\%$ & $N$ & $\%$ & $N$ & $\%$ \\
\hline Normal 24-h blood pressure & 20 & 95 & 26 & 90 & 26 & 87 \\
\hline Borderline 24-h hypertension & 0 & 0 & 1 & 3 & 4 & 3 \\
\hline Mild, moderate, or severe 24-h hypertension & 1 & 5 & 2 & 7 & 0 & 0 \\
\hline Normal daytime blood pressure & 20 & 95 & 27 & 93 & 27 & 90 \\
\hline Borderline daytime hypertension & 0 & 0 & 0 & 0 & 3 & 10 \\
\hline Mild, moderate, or severe daytime hypertension & 1 & 5 & 2 & 7 & 0 & 0 \\
\hline Normal night-time blood pressure & 20 & 95 & 24 & 83 & 26 & 87 \\
\hline Borderline night-time hypertension & 0 & 0 & 3 & 10 & 2 & 1.5 \\
\hline Mild, moderate, or severe night-time hypertension & 1 & 5 & 2 & 7 & 2 & 1.5 \\
\hline Total & 21 & 100 & 29 & 100 & 30 & 100 \\
\hline
\end{tabular}

Normal BP $24 \mathrm{hr} \leq 130 / 80 \mathrm{mmHg}$, Daytime BP $\leq 135 / 85 \mathrm{mmHg}$, Nighttime BP $\leq 120 / 70 \mathrm{mmHg}$, Borderline hypertension between normal blood pressure values and hypertension, Hypertension $24 \mathrm{~h}>135 / 85 \mathrm{mmHg}$, Daytime $>140 / 90 \mathrm{mmHg}$, Nighttime $>125 / 75 \mathrm{mmHg}$

however, with no effect of IUGR on SBP in these very preterm individuals. This would seem to suggest that prematurity alone is a predisposing risk factor for higher SBP. Interestingly, compared with SGA participants, more mothers of AGA participants had suffered from hypertension during pregnancy. Yet, we found no significant associations between prenatal circumstances, such as maternal hypertension and corticosteroid use, and adult blood pressure. Prevalence of hypertension was low, however, so that the analysis lacked power.

These results compare well with our earlier work, which documented a similar mean SBP of $123 \mathrm{mmHg}$ and a high prevalence of hypertension (10\%) in individuals born very prematurely recruited from the same cohort [16]. Likewise, Irving et al. reported higher blood pressure in 24-year-olds born prematurely (mean gestational age 33.4 weeks) and no effect of IUGR [28]. Preterm children in a Finnish study showed cardiovascular changes, including SBP, already at the age of 5 years [29]. A Swedish study of 165,136 men also showed an inverse association between gestational age, ranging from 35-44 weeks, and SBP [14]. Johansson et al. described that blood pressure in preterm children and SGA in term children at the age of 9.6 years did not differ from that in term children with appropriate birth weight. Catecholamine levels were higher in the preterm and SGA groups, however, suggesting increased sympathoadrenal activity [30].

In contrast, Singhal et al. found 15-year-olds born prematurely (mean GA 31 weeks; $N=216$ ) not to be at higher risk of vascular disease compared with term sameage peers [31]. Also, a large cohort study in Brazil could not detect different blood pressure values for 15-year-old individuals born with a gestational age less than or more than 37 weeks [32]. In that study, adolescent blood pressure was elevated only when there was IUGR. One possible explanation for these contrasting results is the obscure effect of early determinants of increased blood pressure during adolescence that Barker et al. described [3, 33].

Bayrakci et al. described abnormal circadian blood pressure regulation in SGA preterm children aged between 5 and 17 years [34]. Nocturnal dipping, especially in those born light for birth date, was less than that of controls. Their SBP was not different from that in controls. Blood pressure data were converted into SDS scores because subjects differed in age, height, and gender, as described by Wühl et al. [35]. For our adult population, such SDS scores were not available. Recently, Bacchetta et al. described increased DBP at the mean age of 7.6 years in very preterm individuals (mean gestational age 27.3 weeks) but no difference between growth-restricted individuals (either intrauterine or extrauterine) [36].

Siewert-Delle and Ljungman suggested that in preterm individuals, gestational age (30-38 weeks) has a great impact on adult blood pressure [15]. In our study, a possible effect of IUGR may therefore have been concealed. We found only a slightly stronger regression coefficient of gestational age to adult SBP for the preterm participants. Significance disappeared, however, in this smaller separate analysis. For that matter, an earlier study in a larger sample of individuals from our cohort who were born very prematurely neither revealed a relation between gestational nor adult SBP [16]. Therefore, our data suggest weaker relation between gestational age and adult SBP in the lowest ranges of gestation.

O'Brien et al. described different mean and 95th percentile 24-h ambulatory blood pressure values (p95) 
for men and women as well as for different age categories [37]. For age range 17-29 years, the p95 were 136/81 for men $(N=107)$ and $125 / 78$ for women $(N=174)$.

On the basis of these reference values, the prevalence of hypertension in our cohort was one in SGA, two in AGA, and two in controls (not significant). Prehypertensive blood pressure is a risk factor for hypertension in later life [38]. Screening at a young adult age could be effective to trace individuals at risk of adult hypertension and would enable early preventive treatment.

\section{Strengths and limitations}

A major strength of this study is that perinatal parameters for prematurely born individuals were obtained prospectively. Second, the study design provided for separate evaluation of the effects of premature birth and IUGR.

The main limitation lies in the relatively small group sizes, notably that of the SGA group. For this reason, reliable prevalence rates of hypertension (stages 1 and 2) and relative risks cannot be given. Much larger samples are needed to confirm our findings. Second, selection bias could have been introduced because recruitment was among individuals who participated in the POPS 19 study, which in itself had a response rate of $62.1 \%$. The nonresponse group in the POPS 19 study differs significantly from the response group by male gender, non-Dutch origin, low maternal education, severe handicap, and special education [21]. However, there was no difference in SGA status. Third, we had to rely on the mother's recall of her child's birth weight and gestational age in $40 \%$ of controls. We assumed that a mother would have remembered premature birth or low birth weight. Most mothers knew the exact term date (40 weeks), from which we calculated gestational age. Birth weight could mostly be retrieved from birth announcement cards and diaries. As indicated earlier, uncertainty about these data was reason for exclusion. The chance of recall bias would therefore seem to be low. Moreover, parental recall of birth weight has been demonstrated to be a reliable variable in a statistical analysis [39, 40]. Lastly, controls were recruited from a medical school and may be considered to be better educated than the general population, especially on health issues. Thus, they may be in better health. Their blood pressure was comparable, however, to that of same-age individuals in large population-based studies [41]. Therefore, we feel they formed a representative control cohort.

In conclusion, our results suggest that very premature birth increases SBP at a young adult age. IUGR does not seem to attenuate this effect. Considering our previous findings of decreased renal size, increased microalbuminuria, and decreased renal blood flow, very preterm individuals who suffered from IUGR are likely to have reduced nephron endowment. Systematic monitoring of blood pressure in young adults born very prematurely may identify individuals at risk for developing hypertension. Such a follow-up program may reveal the clinical significance of our findings.

Acknowledgements This part of the POPS 19 study was supported by a grant from the Dutch Kidney Foundation. We thank TNO, Quality of Life (E.T.M. Hille, P. Verloove-Vanhorick) for the use of the POPS cohort database, F. Boomsma (Erasmus MC, Rotterdam) for the measurement of renin concentration, and M.J.J. Finken (Dept. of Pediatrics and Clinical Epidemiology, LUMC, Leiden) for the calculation of adult anthropometric SD scores.

Financial Support Dutch Kidney Foundation, Grant C-1924. No conflict of Interest

Open Access This article is distributed under the terms of the Creative Commons Attribution Noncommercial License which permits any noncommercial use, distribution, and reproduction in any medium, provided the original author(s) and source are credited.

\section{References}

1. Barker DJ, Osmond C (1988) Low birth weight and hypertension. BMJ 297:134-135

2. Huxley RR, Shiell AW, Law CM (2000) The role of size at birth and postnatal catch-up growth in determining systolic blood pressure: a systematic review of the literature. J Hypertens 18:815-831

3. Law CM, de Swiet M, Osmond C, Fayers PM, Barker DJ, Cruddas AM, Fall CH (1993) Initiation of hypertension in utero and its amplification throughout life. BMJ 306:24-27

4. Barker DJ (1992) The fetal origins of adult hypertension. J Hypertens Suppl 10:S39-S44

5. Woods LL, Weeks DA, Rasch R (2004) Programming of adult blood pressure by maternal protein restriction: role of nephrogenesis. Kidney Int 65:1339-1348

6. Vehaskari VM, Aviles DH, Manning J (2001) Prenatal programming of adult hypertension in the rat. Kidney Int 59:238-245

7. Keller G, Zimmer G, Mall G, Ritz E, Amann K (2003) Nephron number in patients with primary hypertension. N Engl J Med 348:101-108

8. Brenner BM, Anderson S (1992) The interrelationships among filtration surface area, blood pressure, and chronic renal disease. J Cardiovasc Pharmacol 19(Suppl 6):S1-S7

9. Martyn CN, Lever AF, Morton JJ (1996) Plasma concentrations of inactive renin in adult life are related to indicators of foetal growth. J Hypertens 14:881-886

10. Konje JC, Bell SC, Morton JJ, de Chazal R, Taylor DJ (1996) Human fetal kidney morphometry during gestation and the relationship between weight, kidney morphometry and plasma active renin concentration at birth. Clin Sci (Lond) 91:169-175

11. Doyle LW, Faber B, Callanan C, Morley R (2003) Blood pressure in late adolescence and very low birth weight. Pediatrics 111:252-257

12. Kistner A, Celsi G, Vanpee M, Jacobson SH (2000) Increased blood pressure but normal renal function in adult women born preterm. Pediatr Nephrol 15:215-220

13. Kistner A, Celsi G, Vanpee M, Jacobson SH (2005) Increased systolic daily ambulatory blood pressure in adult women born preterm. Pediatr Nephrol 20:232-233

14. Leon DA, Johansson M, Rasmussen F (2000) Gestational age and growth rate of fetal mass are inversely associated with systolic 
blood pressure in young adults: an epidemiologic study of 165 , 136 Swedish men aged 18 years. Am J Epidemiol 152:597-604

15. Siewert-Delle A, Ljungman S (1998) The impact of birth weight and gestational age on blood pressure in adult life: a populationbased study of 49-year-old men. Am J Hypertens 11:946-953

16. Keijzer-Veen MG, Finken MJ, Nauta J, Dekker FW, Hille ET, Frolich M, Wit JM, van der Heijden AJ (2005) Is blood pressure increased 19 years after intrauterine growth restriction and preterm birth? A prospective follow-up study in The Netherlands. Pediatrics 116:725-731

17. Keijzer-Veen MG, Schrevel M, Finken MJ, Dekker FW, Nauta J, Hille ET, Frolich M, van der Heijden BJ (2005) Microalbuminuria and lower glomerular filtration rate at young adult age in subjects born very premature and after intrauterine growth retardation. J Am Soc Nephrol $16: 2762-2768$

18. Keijzer-Veen MG, Kleinveld HA, Lequin MH, Dekker FW, Nauta J, de Rijke YB, van der Heijden BJ (2007) Renal function and size at young adult age after intrauterine growth restriction and very premature birth. Am J Kidney Dis 50:542-551

19. Keijzer-Veen MG, Devos AS, Meradji M, Dekker FW, Nauta J, van der Heijden BJ (2009) Reduced renal length and volume 20 years after very preterm birth. Pediatr Nephrol. doi:10.1007/ s00467-009-1371-y

20. Verloove-Vanhorick SP, Verwey RA, Brand R, Gravenhorst JB, Keirse MJ, Ruys JH (1986) Neonatal mortality risk in relation to gestational age and birthweight. Results of a national survey of preterm and very-low-birthweight infants in the Netherlands. Lancet 1:55-57

21. Hille ET, Elbertse L, Gravenhorst JB, Brand R, Verloove-Vanhorick SP (2005) Nonresponse bias in a follow-up study of 19-year-old adolescents born as preterm infants. Pediatrics 116:e662-e666

22. Fredriks AM, van Buuren S, Burgmeijer RJ, Meulmeester JF, Beuker RJ, Brugman E, Roede MJ, Verloove-Vanhorick SP, Wit JM (2000) Continuing positive secular growth change in The Netherlands 19551997. Pediatr Res 47:316-323

23. Niklasson A, Ericson A, Fryer JG, Karlberg J, Lawrence C, Karlberg P (1991) An update of the Swedish reference standards for weight, length and head circumference at birth for given gestational age (1977-1981). Acta Paediatr Scand 80:756-762

24. Beevers G, Lip GY, O'Brien E (2001) ABC of hypertension. Blood pressure measurement. Part I- sphygmomanometry: factors common to all techniques. BMJ 322:981-985

25. O'Brien E, Asmar R, Beilin L, Imai Y, Mallion JM, Mancia G, Mengden T, Myers M, Padfield P, Palatini P, Parati G, Pickering T, Redon J, Staessen J, Stergiou G, Verdecchia P (2003) European Society of Hypertension recommendations for conventional, ambulatory and home blood pressure measurement. J Hypertens 21:821-848

26. Staessen JA, Beilin L, Parati G, Waeber B, White W (1999) Task force IV: Clinical use of ambulatory blood pressure monitoring. Participants of the 1999 Consensus conference on ambulatory blood pressure monitoring. Blood Press Monit 4:319-331
27. Derkx FH, Tan-Tjiong L, Wenting GJ, Boomsma F, Man in 't Veld AJ, Schalekamp MA (1983) Asynchronous changes in prorenin and renin secretion after captopril in patients with renal artery stenosis. Hypertension 5:244-256

28. Irving RJ, Belton NR, Elton RA, Walker BR (2000) Adult cardiovascular risk factors in premature babies. Lancet 355:2135-2136

29. Mikkola K, Leipala J, Boldt T, Fellman V (2007) Fetal growth restriction in preterm infants and cardiovascular function at five years of age. J Pediatr 151:494-499

30. Johansson S, Norman M, Legnevall L, Dalmaz Y, Lagercrantz H, Vanpee M (2007) Increased catecholamines and heart rate in children with low birth weight: perinatal contributions to sympathoadrenal overactivity. J Intern Med 261:480-487

31. Singhal A, Kattenhorn M, Cole TJ, Deanfield J, Lucas A (2001) Preterm birth, vascular function, and risk factors for atherosclerosis. Lancet 358:1159-1160

32. Barros FC, Victora CG (1999) Increased blood pressure in adolescents who were small for gestational age at birth: a cohort study in Brazil. Int J Epidemiol 28:676-681

33. Barker DJ, Law CM (1994) Birth weight and blood pressure in adolescence. Studies may be misleading. BMJ 308:1634

34. Bayrakci US, Schaefer F, Duzova A, Yigit S, Bakkaloglu A (2007) Abnormal circadian blood pressure regulation in children born preterm. J Pediatr 151:399-403

35. Wuhl E, Witte K, Soergel M, Mehls O, Schaefer F (2002) Distribution of 24-h ambulatory blood pressure in children: normalized reference values and role of body dimensions. J Hypertens 20:1995-2007

36. Bacchetta J, Harambat J, Dubourg L, Guy B, Liutkus A, Canterino I, Kassai B, Putet G, Cochat P (2009) Both extrauterine and intrauterine growth restriction impair renal function in children born very preterm. Kidney Int. doi:10.1038/ki.2009.201

37. O'Brien E, Murphy J, Tyndall A, Atkins N, Mee F, McCarthy G, Staessen J, Cox J, O'Malley K (1991) Twenty-four-hour ambulatory blood pressure in men and women aged 17 to 80 years: the Allied Irish Bank Study. J Hypertens 9:355-360

38. Chobanian AV, Bakris GL, Black HR, Cushman WC, Green LA, Izzo JL jr (2003) The Seventh Report of the Joint National Committee on Prevention, Detection, Evaluation, and Treatment of High Blood Pressure: the JNC 7 report. JAMA 289:2560-2572

39. Delgado-Rodriguez M, Gomez-Olmedo M, Bueno-Cavanillas A, Garcia-Martin M, Galvez-Vargaz R (1995) Recall bias in a casecontrol study of low birth weight. J Clin Epidemiol 48:1133-1140

40. O'Sullivan JJ, Pearce MS, Parker L (2000) Parental recall of birth weight; how accurate is it? Arch Dis Child 82:202-203

41. Muntner P, He J, Cutler JA, Wildman RP, Whelton PK (2004) Trends in blood pressure among children and adolescents. JAMA 291:2107-2113

42. O'Brien E, Beevers G, Lip GY (2001) ABC of hypertension. Blood pressure measurement. Part III-automated sphygmomanometry: ambulatory blood pressure measurement. BMJ 322: $1110-1114$ 